\title{
ANALISIS EFISIENSI BIAYA TENAGA KERJA LANGSUNG PADA PT. ADINATA SUNGGUMINASA
}

\author{
Andi Rustamı Andi Arifwangsa Adiningrat2 \\ 1,2,3 Universitas Muhammadiyah Makassar \\ e-mail: 1andiariefky@unismuh.ac.id, 2,3 andirust99@gmail.com
}

\begin{abstract}
Research is done with the aim of to know the cost-efficient direct manpower undertaken by the company PT. Adinata.. In this study, the literature and observations review was by conducting research on the field through live interviews and data retrieval, related documents from the company as well as the use of books, and internet media. The Data obtained in the analysis using quantitative analysis method is how to compare between real labor cost (Actual) with budgeted, which often happens deviation from budget called Variance. The results showed that based on the analysis observation that researchers have done showed that the efficiency rate of labor cost at PT. Adinata in a time span of 20142016 is $10.5586 \%$. It shows that direct energy cost control is in the category of efficient and stable.
\end{abstract}

Keywords: Biya accounting, management accounting, direct labor cost

\begin{abstract}
Abstrak
Penelitian ini dilakukan dengan tujuan untuk Untuk mengetahui efisien biaya tenaga kerja langsung yang dilakukan oleh perusahaan PT. Adinata. Dalam penelitian ini menggunakan tinjauan kepustakaan dan observasi yaitu dengan melakukan penelitian di lapangan melalui wawancara langsung dan pengambilan data, dokumendokumen yang berkaitan dari perusahaan serta menelah bukubuku, dan media internet. Data yang diperoleh di analisis dengan menggunakan metode analisis kuantitatif yaitu cara membandingkan antara biaya tenaga kerja yang sesungguhnya terjadi (Actual) dengan dianggarkan, dimana sering terjadi penyimpangan dari anggaran yang disebut Variance. Hasil penelitian menunjukkan bahwa Berdasarkan pengamatan analisis yang telah peneliti lakukan menunjukkan bahwa tingkat efisiensi biaya tenaga kerja pada PT. Adinata dalam rentang waktu $2014-$ 2016 dalah sebesar 10, 5586 \%. Hal ini menunjukkan bahwa Pengendalian Biaya Tenaga Langsung berada dalam kategori Efisien dan stabil (In Control).
\end{abstract}

Kata Kunci: Akuntansi Biya, Akuntansi Manajemen, Biaya Tenaga Kerja Langsung. 


\section{PENDAHULUAN}

Perusahaan sebagai wadah penggerak perekonomian memiliki peranan penting dalam mengatur perekonomian suatu bangsa. Oleh karena itu, perusahaan sudah sewajarnya jika senantiasa mengoptimalisasikan perolehan labanya dalam rangka mempertahankan kelangsungan kehidupan perusahaannya. Penganggaran biaya-biaya produksi dapat memberikan petunjuk untuk menentukan besarnya kebutuhan dana juga dapat di jadikan sebagai pedoman garis-garis besar tentang apa yang hendak dituju. Anggaran yang direncanakan akan menunjukkan suatu kegiatan yang terintegrasi, yang dinyatakan dalam bentuk angka- angka, kemudian dibandingkaan dengan hasil yang dicapai.

Penilaian mengenai pengendalian biaya tenaga kerja dilakukan dengan membandingkan realisasi biaya tenaga kerja dengan biaya yang sudah dianggarkan. Dari perbandingan tersebut dapatlah diketahui jumlah penyimpangan atau selisih biaya yang terjadi (Variance). Dari hasil selisih tersebut dapat diketahui apakah selisih biaya tersebut menunjukkan selisih biaya yang menguntungkan (Favorable Variance) atau sebaliknya menunjukkan selisih biaya yang merugikan (Unfavorable Variance). PT. Adinata dalam kegiatan sehariharinya terdapat kelemahan-kelemahan didalam pengendalian biaya-biaya produksi tenaga kerja, sehingga tidak sesuai antara biaya tenaga kerja yang terjadi dengan biaya tenaga kerja yang dianggarkan.

\section{TINJAUAN PUSTAKA}

\section{Pengertian Pengendalian}

Pengendalian diperlukan untuk mengetahui penyimpangan yang tidak sesuai dengan anggaran (budget) yang ditetapkan atau dengan kata lain, pengendalian adalah merupakan koreksi sampai sejauh mana anggaran (budget) dilakukan dengan baik.

\section{Pengertian dan Klasifikasi Biaya}

Suatu perusahaan yang digolongkan sebagai perusahaan manufaktur yang melakukan proses pengolahan masukan (input) menjadi (output). Pada dasarnya mempunyai tujuan untuk memperoleh pendapatan atau laba.Pendapatan harus lebih besar dibandingkan jumlah biaya yang dikeluarkan.
Menurut Mulyadi (2009:8) menyatakan bahwa biaya dalam arti luas adalah biaya merupakan pengorbanan sumber ekonomi, yang diukur dalam satuan uang, yang telah terjadi atau kemungkinan akan terjadi untuk tujuan tertentu.

\section{Pengertian Biaya Tenaga Kerja}

Didalam perusahaan pada umumnya biaya tenaga kerja merupakan biaya produksi yang cukup tinggi sehingga perlu untuk diadakan pengendalian biaya produksi yang cukup tinggi sehingga perlu untuk diadakan pengendalian biaya tenaga kerja. Dengan tujuan pengendalian tenaga kerja bagi manajemen yaitu mencapai efisiensi tenga kerja termasuk konpensasi gaji dan upah yang memadai, agar menjadi kualitas produk yang dihasilkan sudah memenuhi standar dan dapat dicapainya mutu pelayanan yang memuaskan.

\section{METODE}

\section{Metode Pengumpulan Data}

Untuk pengumpulan data dilakukan dengan berbagai tehknik pengumpulan data; penelitian kepustakaan, wawancara, dlpengamatan dan dokumentasi.

\section{Jenis dan Sumber Data}

Dalam penulisan digunakan data primer dan data sekunder. Kedua jenis data tersebut diperoleh dari:

a. Data Primer, yaitu data yang diperoleh penulis dari obyek penelitian berdasarkan observasi dan wawancara dengan pimpinan, staf, dan Karyawan Perusahaan.

b. Data Sekunder, yaitu data yang diperoleh penulis dari obyek penelitian berdasarkan observasi dan wawancara/interview dengan Pimpinan, Staf dan Karyawan Perusahaan yang diteliti.

\section{HASIL DAN PEMBAHASAN}

\section{Hasil Penelitian}

Bahan baku merupakan bahan yang membentuk bagian menyeluruh produk sehingga bahan baku menjadi komponen utama yang membentuk satu kesatuan yang tidak terpisahkan dari suatu produk jadi (Slamet, 2017:65). Pembelian bahan baku oleh PT. Adinata yaitu tidak hanya dari satu pemasok tetapi dari banyak pemasok (multiple supplier) 
untuk menjaga kelancaran proses penghematan

biaya.

Tabel 1. Biaya Bahan Baku

\begin{tabular}{ccc}
\hline Tahun & Standar Biaya Bahan Baku & Realisasi Biaya Bahan Baku \\
\hline 2014 & Rp.20, 125,633,000,00 & Rp.20,050,400,000,00 \\
\hline 2015 & Rp.21, 717,120,000,00 & Rp.21,616,105,000,00 \\
\hline 2016 & Rp.22, 415,235,000,00 & Rp.22,213,437,000,00 \\
\hline
\end{tabular}

Sumber: Data primer 2017

Berdasarkan data tabel diatas dapat dideskripsikan bahwa standar biaya bahan baku pada tahun 2014 yaitu sebesar Rp. $20.125,633,000,00$ sedangkan realisasi biaya bahan baku sebesarRp. 20.050,400,000,00. Pada tahun 2015 mengalami peningkatan menjadi Rp. $21,717,120,000,00$ sedangkan realisasi biaya bahan baku sebesarRp. 21,616,105,000,00. Begitupun pada tahun 2016 yang mencapai kisaran tertinggi yaitu Rp. 22,415,235,000,00. Sedangkan realisasi biaya bahan baku sebesarRp. 22,213,437,000,00

\section{Biaya Tenaga Kerja Langsung PT. ADINATA}

Untuk menentukan biaya tenaga kerja yang dibutuhkan perusahaan dalam satu periode, tergantung pada rencana jumlah tenaga kerja yang dibutuhkan pada periode tersebut. Disamping itu jumlah produksi yang menjadi target (sasaran) ditentukan dengan mempertimbangkan kondisi pabrik serta faktorfaktor alam yang mempengaruhi tersedianya bahan baku, misalnya cuaca, lamanya pengangkutan dan sebagainya. Karena permintaan pasar tidak menetap, maka jumlah produksi yang menjadi sasaran produksi sifatnya hanya sebagai patokan sementara.

\section{Standar Kerja PT. ADINATA}

Jumlah jam kerja yang diterapkan untuk tenaga kerja langsung. Hal ini sesuai dengan peraturan pemerintah tentang standar jam kerja. Jadi penerapan jam kerja PT. ADINATA sebagai berikut:

Tabel 2. Biaya Tenaga Kerja Langsung 2014 - 2016.

\begin{tabular}{ccccc}
\hline No & Data Standar & $\mathbf{2 0 1 4}$ & $\mathbf{2 0 1 5}$ & $\mathbf{2 0 1 6}$ \\
\hline 1. & Jumlah Karyawan & 810 & 810 & 810 \\
\hline 2. & Jumlah Jam Kerja & 2496 & 2496 & 2496 \\
\hline 3. & Jumlah Jam Lembur & 220 & 234 & 230 \\
\hline 4. & UMK / Bulan & $787,000,00$ & $890,000,00$ & $1.200 .000,00$ \\
\hline 5. & Upah Lembur/Tahun & $572.000,00$ & $629,200,00$ & $672,000,00$ \\
\hline 6. & Upah Lembur/Jam & 2,000 & $2,100,00$ & $2,350,000$ \\
\hline 7. & Jumlah Upah & Rp. $\mathbf{6 3 7 , 4 7 0 , 0 0 0 , 0 0}$ & Rp. $\mathbf{7 2 0 , 9 0 0 , 0 0 0 , 0 0}$ & $\mathbf{R p . 9 7 2 , 0 0 0 , 0 0 0 , 0 0}$ \\
\hline Sumber $:$ Data Primer 2017 & & & \\
\hline
\end{tabular}

Tenaga kerja pada PT Adinata digolongkan dalam 4 kelompok yaitu:

a) Karyawan staff (karyawan tetap), yang tidak berhubungan langsung dengan kegiatan produksi. Seperti karyawan administrasi dan umum.

b) Karyawan bulanan, merupakan karyawan tetap dan tidak berhubungan langsung dengan kegiatan produksi. Misalnya supervisor dan mandor.

c) Karyawan harian, merupakan karyawan tetap dan berhubungan langsung dengan kegiatan produksi. Karyawan tetap harian ini bekerja berdasarkan pembagian waktu ( shift ), yaitu: Shift 1 : Pukul 08.00-16.00
Shift 2 : Pukul 16.00-24.00

Shift 3 : Pukul 24.00-08.00 ( esok harinya )

d) Karyawan borongan, merupakan karyawan lepas dan jumlahnya tidak menentu dalam setiap periode. Karyawan ini berhubungan langsung dengan kegiatan produksi.

\section{Standar Tarif Upah PT. ADINATA}

Salah satu cara yang digunakan untuk menentukan standar tarif upah dapat berdasarkan atas sistem penggajian yang dilaksanakan oleh perusahaan melalui standar upah harian, per jam, per unit yang dihasilkan dan sebagainya. Sebagai beriku 
Tabel 3. Standar Tarif Upah Tenaga PT. ADINATA

\begin{tabular}{ccc}
\hline Tahun & $\begin{array}{c}\text { Standar Tarif Upah } \\
\text { Langsung }\end{array}$ & $\begin{array}{c}\text { Standar Jam Kerja } \\
\text { Tenaga Langsung }\end{array}$ \\
\hline 2014 & Rp. 637.470.000.00 & 220 \\
\hline 2015 & Rp. $720,990.000 .00$ & 234 \\
\hline 2016 & Rp. 972.000 .000 .00 & 230 \\
\hline
\end{tabular}

Sumber: Data Primer yang diolah 2017

\section{Pembahasan}

\section{Realisasi Biaya Tenaga Kerja Langsung}

Realisasi pelaksanaan anggaran dibuat secara triwulan oleh setiap kepala bagian, lalu laporan tersebut diserahkan ke bagian keuangan. Selanjutnya bagian keuangan akan membuat rekapitulasi biaya dan dalam rekapitulasi itu itu diserahkan pula akumulasi biaya menurut
Rancangan Anggaran Biaya (RAB). Jika biaya sesungguhnya lebih kecil bila dibandingkan dengan yang dianggarkan, maka dianggap selisih menguntungkan, namun sebaliknya jika biaya sesungguhnya lebih besar bila dibandingkan dengan yang dianggarkan, maka dianggap selisih merugikan.

Tabel 4. Data Jam Kerja dan Upah Tenaga Kerja Langsung pada PT. ADINATA yang terjadi pada tahun 2014-2016.

\begin{tabular}{|c|c|c|c|c|c|c|c|}
\hline \multirow{2}{*}{ No } & \multirow{2}{*}{ Departemen } & \multicolumn{4}{|c|}{ Standar } & \multicolumn{2}{|c|}{ Realisasi } \\
\hline & & Jam Kerja & Tarif & Jumlah & Jam Kerja & Tarif & Jumlah \\
\hline 1. & Hasil Bumi & 121.800 & 2000 & 243.600 .000 & $133.087,5$ & 2000 & 266.174 .500 \\
\hline 2. & Bahan Baku & 40.600 & 2000 & 81.200 .000 & 40.950 & 2000 & 81.900 .000 \\
\hline 3. & Produksi & 182.700 & 2000 & 365.400 .000 & $194.512,5$ & 2000 & 389.024 .500 \\
\hline 4. & Packing & 60.700 & 2000 & 121.400 .000 & 61.425 & 2000 & 122.850 .000 \\
\hline 5. & Barang Jadi & 56.840 & 2000 & 113.680 .000 & 57.330 & 2000 & 114.660 .000 \\
\hline
\end{tabular}

Sumber : PT. ADINATA ( data diolah sendiri) 2017

\section{Departemen Hasil Bumi}

a. Selisih Tarif Upah

Penyimpangan tarif upah langsung timbul karena perusahaan telah membayar upah langsung kepada pekerja dengan tarif yang lebih tinggi atau lebih rendah dibandingkan tarif upah standar. Rumus yang digunakan untuk menghitung penyimpangan tarif upah langsung adalah sebagai berikut

STU $=($ Tss - Tst $) \times$ JKss

Tabel 5. Analisis Anggaran Biaya Tenaga Kerja Langsung PT. Adinata Periode Tahun 2014-2016

\begin{tabular}{ccccc}
\hline No & Departemen & Anggaran & Realisasi & Varians ( Rp ) \\
\hline 1 & Hasil Bumi & $243.600 .000,00$ & $266.174 .500,00$ & $22.574 .500,00$ \\
\hline 2 & Bahan Baku & $81.200 .000,00$ & $81.900 .000,00$ & $700.000,00$ \\
\hline 3 & Produksi & $365.400 .000,00$ & $389.024 .500,00$ & $23.624 .500,00$ \\
\hline 4 & Packing & $121.400 .000,00$ & $122.850 .000,00$ & $1.050 .000,00$ \\
\hline 5 & Barang Jadi & $113.680 .000,00$ & $114.660 .000,00$ & $980.000,00$ \\
\hline & Total & $925.280 .000,00$ & $974.609 .000,00$ & $48.929 .000,00$ \\
\hline
\end{tabular}

Secara keseluruhan Anggaran PT. ADINATA sebesar Rp.925.280.000,00 dan terealisasi sebesar Rp.974.609.000,00 berarti terjadi penyimpangan yang merugikan sebesar Rp.49.329.000,00 biaya ini perlu dikendalikan karena apabila biaya tenaga kerjanya besar, maka akan mempengaruhi jumlah biaya produksi yaitu akan semakin besar dan tentu saja akan mempengaruhi besarnya harga pokok penjualan.
Faktor yang menyebabkan terjadinya varians efisiensi biaya tenaga kerja langsung adalah barang pesanan yang terlambat datang mengakibatkan bertambahnya jam kerja para karyawan dari yang telah ditetapkan sebelumnya sehingga terjadi varians efisiensi. Salah satunya juga berasal dari faktor cuaca yang tidak baik juga mempengaruhi lamanya waktu penyelesaian Produksi Kecap karena apabila terjadi hujan maka para karyawan 
berhenti bekerja namun jam kerja tetap dihitung sehingga memakan jam kerja yang melebihi jam standar yang telah ditetapkan sebelumnya. Hal ini dapat kita lihat pada table berikut ini:

Tabel 6. Tingkat Efisiensi Biaya Tenaga Kerja Langsung PT. Adinata

\begin{tabular}{ccccc}
\hline $\begin{array}{c}\text { Standar jam TenagaKerja } \\
\text { Langsung }\end{array}$ & Kriteria & Nilai & Varians Tarif & Varians Efisiensi \\
\hline 220 & Efisien & 4 & $45.45 \%$ & $22.24 \%$ \\
\hline 234 & Efisien & 4 & $42.73 \%$ & $20.90 \%$ \\
\hline 230 & Efisien & 4 & $43.47 \%$ & $21.27 \%$ \\
\hline
\end{tabular}

Sumber: Data PT.Adinata yang telah diolah kembali 2018

Tingkat Efisiensi Biaya Tenaga Kerja Langsung PT. Adinata memiliki Varians Tingkat Efisiensi untuk Standar Jam Tenaga Kerja Langsung220 memiliki Varians Tarifsebesar $45.45 \%$ dan Varians Efisiensi sebesar $22.24 \%$ dengan Kriteria Nilai 4, Efisien. 234 memiliki Varians Tarifsebesar $42.73 \%$ dan Varians Efisiensi sebesar $20.90 \%$ dengan Kriteria Nilai 4, Efisien. 230 memiliki Varians Tarifsebesar $43.47 \%$ dan Varians Efisiensi sebesar $21.27 \%$ dengan Kriteria Nilai 4, Efisien.

\section{Efisiensi Biaya Bahan Baku dan Biaya Tenaga kerja Langsung}

Penilaian Efisiensi Bahan Baku dengan Uji Beda Nilai.

Tabel 7. Tabel uji beda Nilai Bahan Baku

\begin{tabular}{ccc}
\hline Tahun & $\begin{array}{c}\text { Rata-rata } \\
(\mathrm{x})\end{array}$ & $\begin{array}{c}\text { Jarak Sampel } \\
(\mathrm{R})\end{array}$ \\
\hline 2014 & 3.50 & 1 \\
\hline 2015 & 1.00 & 0 \\
\hline 2016 & 3.00 & 2 \\
\hline & 7.50 & 3.00 \\
\hline
\end{tabular}

Penilaian Efisiensi Tenaga Kerja Langsung dengan Uji Beda Nilai

Tabel 8. Tabel Uji Beda Nilai Tenaga Kerja Langsung

\begin{tabular}{ccc}
\hline Tahun & Rata-rata $(\mathrm{x})$ & Jarak Sampel $(\mathrm{R})$ \\
\hline 2014 & 4.00 & 0 \\
\hline 2015 & 4.00 & 0 \\
\hline 2016 & 4.00 & 0 \\
\hline & 12.00 & 0.00 \\
\hline
\end{tabular}

Sumber: Data primer yang diolah 2018

Berdasarkan tabel diatas dapat dianalisis bahwa efisiensi biaya Bahan Baku dan biaya Tenaga Kerja Langsung dengan menggunakan uji beda nilai antara tahun 2014, 2015 dan 2016. Baik biaya bahan baku maupun tenaga kerja langsung termasuk dalam kategori efisien. Untuk penyelidikan lebih lanjut terhadap efisiensi biaya tidak perlu dilakukan karena
pengendalian.Tenaga Kerja Langsung masih berada pada daerah In Control.

Tabel 9. Tingkat Efisiensi Biaya Tenaga Kerja Langsung PT. ADINATA Tahun 2014-2016

\begin{tabular}{cccc}
\hline Tahun & Jenis Kontrol Biaya & Kriteria & Nilai \\
\hline 2014 & $\begin{array}{c}\text { Biaya Tenaga Kerja } \\
\text { Langsung }\end{array}$ & efissien & 4 \\
\hline 2015 & $\begin{array}{c}\text { Biaya Tenaga Kerja } \\
\text { Langsung }\end{array}$ & efisien & 4 \\
\hline 2016 & $\begin{array}{c}\text { Biaya Tenaga Kerja } \\
\text { Langsung }\end{array}$ & efissien & 4 \\
\hline
\end{tabular}

Sumber: Data Primer PT. Adinata 2017

Untuk penyetaraan efisiensi biaya produksi PT. ADINATA maka data variansi biaya produksi dan tenaga kerja langsung dapat dibuat penilaian berdasarkan table diatas bahwa pada tahun 2014 Biaya Tenaga Kerja Langsung berada pada kriteria Efisien dengan nilai 4. Pada tahun 2015 Biaya Tenaga Kerja Langungberada pada criteria Efisien dengan nilai 4.Pada tahun 2016 Biaya Tenaga Kerja Langsung berada pada kriteria Efisien dengan nilai 4.

Deskriptif Presentase Tenaga Kerja Langsung Analisis deskriptif Presentase Tahun 20142016

Tenaga Kerja Langsung = 974.609.000.00

$$
\text { Hasil } \quad \begin{aligned}
& 925.280 .000 .00 \\
& =10,5586 \%
\end{aligned}
$$

\section{Analisis dan Manfaatnya}

Berdasarkan pengamatan analisis yang lakukan menunjukkan bahwa tingkat efisiensi biaya tenaga kerja pada PT. Adinata dalam rentang waktu 2014 - 2016 dalah sebesar $10,5586 \%$. Hal ini menunjukkan bahwa Pengendalian Biaya Tenaga Langsung berada dalam kategori Efisien dan stabil (In Control). dimana PT. ADINATA Sungguminasa memiliki tingkat efisiensi yang sangat stabil baik biaya bahan baku maupun biaya tenaga kerja langsung. 


\section{KESIMPULAN DAN SARAN}

\section{Kesimpulan}

Hasil analisis data dan pembahasan maka dapat disimpulkan sebagai berikut: Berdasarkan analisis deskriptif presentase, tingkat efisiensi biaya tenaga kerja langsung menemukan adanya kestabilan. Hal ini sama atau sejalan dengan hasil uji beda nilai begitupun dengan pengendalian biaya Tenaga Kerja Langsung yang berada pada daerah in control. Meskipun ditemukan elisih yang merugikan yaitu terjadi selisih pada jam kerja (selisih efisiensi upah), yang diakibatkan oleh beberapa hal antara lain dikarenakan:

a. Dalam pelaksanaan kegiatan produksi tenaga kerja langsung tidak dapat bekerja dengan efisien dan kurangnya pengawasan terhadap tenaga kerja langsung.

b. Perusahaan tidak konsisten dengan jumlah tenaga kerja yang dianggarkan dan direalisasikan. Adanya penambahan tenaga kerja ternyata tidak efektif yang menyebabkan adanya pemborosan tenaga kerja yang menimbulkan peningkatan biaya tenaga kerja langsung.

c. Sedangkan tarif upah standar tidak mengalami perubahan tarif upah yang terealisasi dengan yang dianggarkan, karena tarif yang ditetapkan tidak mengalami perubahan dalam tahun tersebut.

\section{Saran}

Adapun saran yang dapat diberikan adalah :

a. Penetapan standar untuk biaya bahan baku dan dan biaya tenaga kerja langsung hendaknya lebih cermat dengan memperhatikan berbagai faktor baik dari luar maupun dari dalam agar varians yang terjadi dapat diminimalisir

b. Proses pengendalian biaya tenaga kerja perlu ditingkatkan, khususnya dalam hal pengawasan tenaga kerja langsung agar tenaga kerja dapat bekerja dengan lebih efisien. Karena banyaknya tenaga kerja yang menganggur pada waktu jam kerja, maka perlu adanya penambahan beberapa orang pengawas dan peningkatan pengawasan tenaga kerja lebih diperhatikan lagi.

c. Perusahaan sebaiknya konsisten dengan jumlah tenaga kerja yang dianggarkan dan yang direalisasikan agar tidak terjadi pemborosan tenaga kerjanya sebaiknya dipikirkan lebih matang lagi agar tidak menimbulkan kerugian.

d. Tujuan jangka panjang sebaiknya PT. ADINATA menanam sendiri semua bahan baku atau mengadakan kerja sama denan para petani. Sedangkan untuk jangka pendek sebaiknya PT. ADINATA menambah supplier - supplier baru untuk pembelian bahan baku yang baru.

\section{REFERENSI}

Adisaputro, Gunawan dan Arsi, Marwan, 1993. Anggaran perusahaan. Edisi Ketiga, Yogyakarta: BPFE-UGM.

Hartadi, Bambang, 1996. Sistem pengendalian intern dalam hubungannya dengan manajemen dan audit. Edisi I, Yogyakarta: BPFE-UGM.

Hartanto, D.1981. Akuntansi untuk usahawan. Jakarta: Lembaga Penelitian Fakultas Ekonomi - UI.

H.P.Simangunsong, 1989. Pokok-pokok pengendalian intern.

Journal book, 2014. Budgeting peranggaran perencanaan lengkap untuk membantu manajemen. 06/01/2018 10:24.

Kartasapoetra S, G Bambang, 1992. Kalkulasi dan pengendalian biaya produksi. Cetakan kedua, Jakarta: Rineka Cipta.

Matz dan Usry. 1998. Akuntansi biaya perencanaan dan pengendalian. Edisi kedelapan. Diedit oleh Alfonsus Sirait dan Hermanto Wibowa. Yogyakarta: Penerbit Erlangga.

Mulyadi. 1986. Akuntansi biaya perencanaan dan pengendalian. Edisi kedelapan. Diedit oleh Alfonsus Sirait dan Hermanto Wibowo. Yogyakarta: Penerbit Erlangga.

Munandar, M. 1995. Budgeting perencanaan kerja pengkoordinasian kerja dan pengawasan kerja. Edisi pertama, Yogyakarta: BPFE-UGM.

Supriono, R. A. 1992. Akuntansi biaya pengumpulan biaya dan penuntun harga pokok. Edisi kedua: Yogyakarta : BPFE-

Baridwan, Zaki. 1991. Sistem akuntansi penyusunan prosedur dan metode. Edisi 5. 